\title{
A Survey Study on Academic Vocabulary Learning Strategies by EFL University Students
}

\author{
Le Pham Hoai Huong \\ Hue University of Foreign Languages, Hue University, Vietnam
}

\begin{abstract}
The development of the Academic Word List by Coxhead (2000) has drawn attention of the academia to teaching and learning academic vocabulary as well as the creation of more word lists for different majors. However, most of the research in the field of vocabulary has focused on the learning strategies for general vocabulary only (e.g. Gu \& Johnson, 1996; Lawson, \& Hogben, 1996; Nation, 2001; Schmitt \& McCarthy, 1997). Little has been done to investigate strategies for academic vocabulary (Nushi \& Jenabzadeh 2016). Given the importance of academic vocabulary in comprising some $8 \%-10 \%$ of running words in academic texts (Nation, 2001), the present study was set out to investigate EFL university students' strategies for learning academic English words. The participants included 132 EFL university students. The study adopted the taxonomy of vocabulary learning strategies by Schmitt (2000) and strategies for learning academic words by Bramki and Williams (1984) and Chung and Nation (2003). The findings reveal that the respondents tended to use on-line dictionaries and other applications more than cognitive strategies in learning academic words. Based on the findings of the study, suggestions were put forward to a systematized list of academic vocabulary learning strategies as well as what teachers and learners should do when encountering new academic words.
\end{abstract}

Index Terms—academic English vocabulary, learning strategy, survey study

\section{INTRODUCTION}

Vocabulary learning strategies have been researched by linguists and language teachers for a long time. Findings from studies on vocabulary learning strategies prove to be of practical values in the educational context because they help both teachers and learners in teaching and learning more effectively. As academic vocabulary has been paid more attention nowadays, there arises the question about the strategies that learners use for academic vocabulary learning and whether there are differences in strategies for learning general vocabulary and academic vocabulary.

Academic vocabulary

Academic vocabulary exists in most academic texts. Townsend (2009, p. 242) defined general academic vocabulary as words "which are used across content areas, have abstract definitions, and are a challenge to master". Similarly, Coxhead (2000, p. 218) regarded academic words as "lexical items [that] occur frequently and uniformly across a wide range of academic materials". Academic vocabulary is considered to comprise some $8 \%-10 \%$ of running words in academic texts (Nation, 2001). Vocabulary has drawn attention of linguists and researchers since Averil Coxhead published the academic word list with 570 words. An academic word includes a stem plus "all inflections and the most frequent, productive, and regular prefixes and suffixes" (Coxhead, 2000, p. 218). Similarly, Yang (2015, p. 28) points out, "Academic words refer to words that account for a relatively high proportion of running words in all academic texts". For example, the estimate family consists of 15 words that include the inflected forms estimates and estimated and the prefixed derivatives overestimate and underestimate. The creation of the academic word list has proved to be useful to students at tertiary level because it appears reasonably frequently in academic writing. "Academic vocabulary is used across all academic disciplines to teach about the content of the discipline" (Mukoroli, 2011, p.9). For learners at tertiary level, academic vocabulary is part of their study; however, learning academic vocabulary is a challenge to them because it is more specific and sometimes abstract.

It is apparent that academic words are embedded in academic texts and materials. Therefore, knowing these words can lead to students' development in their writing and reading (Khani \& Tazik, 2013) and success in higher education (Corson, 1997). It is reported that academic vocabulary is most problematic for learners to learn because academic words are generally not taught in a manner like any other subjects (Thurston \& Candlin, 1998). In addition, as academic vocabulary appears in a wide range of academic texts, when equipped with academic vocabulary learning strategies, students can acquire new academic words (Coxhead \& Nation, 2001; Marzano \& Pickering, 2005).

Baumann and Graves (2010, p. 6), however, divide academic vocabulary into two categories. The first is domain specific academic vocabulary which is also called the content-specific words. These are used in disciplines like mathematics, tourism, and biology, etc. The second is general academic vocabulary. This type of vocabulary is the broad, all-purpose terms that appear across content areas. General academic vocabulary seems to exist in any content areas but may vary in meaning because of the discipline itself. In this study, academic vocabulary refers to the general sense of words that appear in academic texts. 


\section{Vocabulary learning strategies}

Vocabulary learning strategies are well discussed in the literature. They can be described as stages taken by the learners in learning new words. According to Gu (2003), a strategy takes place when the learner analyzes the task, the situation, and what is available in his/her own repertoire. Then, he/she selects, deploys, monitors, and evaluates the effectiveness of this action. Finally, he/she decides whether to revise the plan and action. The literature up to date shows various taxonomies of vocabulary learning strategies; among them are the ones created by Nation (2001) and Schmitt (2000). The taxonomy by Nation (2001) tries to separate aspects of vocabulary knowledge (what is involved in knowing a word) from sources of vocabulary knowledge, and learning process. He mentioned three major categories of vocabulary strategies, namely, planning, finding information, establishing knowledge, and included a wide range of strategies of different complexity. More specifically, according to Nation (2000), at the planning stage, learners choose what words to focus on and when to focus on. First, they will choose the words and the aspects of word knowledge, then the strategies and plan repetition. The next step is to find information about the words by analyzing the words, using context, and consulting a reference source in the first language and the second language. The last step is to establish knowledge with noticing, retrieving and generating.

Schmitt (2000)'s taxonomy includes such categories as: Determination, social, memory, cognitive and metacognitive strategies. Determination strategies comprise of techniques used by leaners in discovering a new word's meaning without recourse to another person's expertise" (Schmitt \& McCarthy, 1997, p.205). The determination strategy supports gaining word knowledge as learners can guess the meanings of words by discerning the new word's part of speech.

Social strategy indicates learners' interactions with others for discovering a word. In this sense, group work can be used to learn or practise vocabulary and students asked teachers to check their work for accuracy (Kramsch, 1979). According to Schmitt (2000), teachers are the most popular reference for this type of strategy in a variety of ways. As the source of reference, teachers can give the L1 translation to students regarding new words, give a synonym, a definition by paraphrasing, use the new words in a sentence, or any combination of these.

Memory strategy involves "relating the word to be retained with some previously learned knowledge, using some form of imagery, or grouping" (Schmitt \& Mc Carthy, 1997, p.207). With the memory strategy, also known as mnemonics strategy, learners try to remember words and consolidate them for later use. By this way, learners can learn faster and recall better with retrieval cues such as pictures of word meaning or a personal experience of the underlying concept. In other words, mnemonics are used with this strategy for help with word retrieval.

Cognitive strategy is the technique that helps learners link new information with existing knowledge, as well as to analyze and classify it (Oxford, 1990). In this technique, learners focus more on repetition and using mechanical means to study vocabulary. Some examples are written and verbal repetition word lists, flash cards, and study aids such as notes and labels.

Metacognitive strategy involves a conscious overview of the learning process and making decisions about planning, mentoring, or evaluating the best ways to study (Oxford, 1990). Learners should make use of books, magazines, newspapers, and movies in English as well as interact with native speakers to increase language input. As learners can never learn all the words, they need to concentrate their limited resources on learning the most useful ones. This means that the conscious decision on which words to learn is one of the important strategies in vocabulary learning.

Bramki and Williams (1984, p. 170) pointed out that in learning vocabulary, learners need to resort to vocabulary recognition as one of the key strategies as when reading a text, readers work out the meaning of an unfamiliar word encountered in a the text. According to these authors, the efficient reader possesses certain strategies for working out that meaning but the inefficient reader does not. Those strategies are common to both general and academic vocabulary learning.

\section{Academic vocabulary learning strategies}

The taxonomy of learning strategies by Schmitt (2000) can be applied to vocabulary in general and academic vocabulary in particular because the former covers the latter and vocabulary is a generic term covering words in any fields of study. Bramki and Williams (1984) and Williams (1980), however, suggest some strategies that are more specific to academic vocabulary. These strategies include inferring from context, unchaining nominal compounds, searching for synonyms, word analysis, and recognizing lexical familiarization devices. Bramki and Williams (1984) also pointed out lexical familiarization as the parent strategy of vocabulary recognition which basically involves several strategies for working out the meaning of some unfamiliar words occurring in scientific texts. Williams (1980, p. 314) described lexical familiarization as, "the author's intention to familiarize the newly-introduced lexical items to the target reader, by verbal, illustrative or numerical devices, or any combination of these means". In other words, lexical familiarization is defined as a contextual aid, intentionally provided by the author for a specific reader (Bramki and Williams, 1984). According to Bramki and Williams (1984), lexical familiarization is a sub-set category of guessing from context and it is a vocabulary recognition strategy.

Lexical familiarization includes exemplification, explanation, stipulation, definition, and illustration (Bramki \& Williams, 1984, p. 175). Exemplification provides the readers with an instance of what the newly-introduced term refers to by giving examples. For example, in this sentence "Durable consumer goods include such things as books, furniture, television sets, motor cars and domestic electric appliances” (Bramki \& Williams, 1984, p. 175), durable consumer 
goods are exemplified with books, furniture, etc. Explanation provides more words, a phrase, a sentence or several sentences which are equivalent or opposed in meaning to the newly-introduced term. An example is "Saving is the act of foregoing consumption". Definition comprises of giving the term, the class to which the term belongs and the differentia or distinguishing features. In this sentence, "Consumer goods are those commodities which satisfy our wants directly", consumers goods are defined. Another technique is stipulation. "Stipulation is a type of definition which indicates that the term being defined has its particular meaning only in a given situation and that it does not necessarily have the same meaning in other situations" (Konecni, 1978, p.378). Synonymy provides the reader with a more familiar lexical item which has almost the same meaning. The last strategy of lexicalization is illustration which is a non-verbal method because it familiarizes the reader through tables, pictures, charts, and diagrams. It is a combination of a text and a visual aid to clarify concepts. In a word, lexical familiarization is always adjacent with newly introduced words which are always written in different typefaces, such as italicization, bold form, underlining, or any other typographic devices. As for Chung and Nation (2003), for academic words, especially technical words, such strategies as recognizing, interpreting definitions, relating senses to a core meaning, and learning word parts can be employed.

The current study adopted the taxonomy by Schmitt (2000) together with the academic vocabulary learning strategies by Bramki and Williams (1984) and Chung and Nation (2003). The strategies for learning academic vocabulary therefore include 6 clusters: Determination, social, memory, cognitive, metacognitive, and device-assisted strategies. Strategies proposed by Bramki and Williams (1984) were integrated into the cluster of meta-cognitive strategy by Schmitt (2000) due to the similarities of the strategies given by the authors. The cluster of device-assisted strategies is a new category added to the taxonomy by Schmitt (2000).

Previous studies

Some studies related to academic vocabulary learning strategies have been conducted. Lessard-Clouston (2008), for example, explored what kinds of academic vocabulary learning strategies were used by native and non-native English students of Christian Graduate School of Theology in Canada. The findings pointed out that the participants used such vocabulary learning strategies such as consulting to dictionary and glossary, practicing new words in paper, taking written notes in class, writing word lists, listing words in computer files, and making index and flashcards. They also listened to recordings or teachers, repeated the words orally and written, quizzing, and asked the new words to others. Lessard-Clouston (1980) found that the participants used such vocabulary learning strategies as writing, using the lexical items, contextual associations to learn academic words (technical words in this case). The author also pointed out that linguistic associations were present in the study but immediate or spaced repetition and imagery, were absent from the present results. Lessard-Clouston (2008) concluded that these learners need structured approaches in order to gain greater depth knowledge of the academic vocabulary in their field.

The study by Akbari and Tahririan (2009) identified the vocabulary learning strategies used by the students in learning specialized (academic words) and non-specialized vocabulary. It involved 137 participants from paramedical undergraduates of Isfahan University of Medical Sciences in Iran. Data collection tools included observation, interview and questionnaire. Similar to the findings of the study by Lessard-Clouston (2008), this study found that the participants mostly used consolidating, dictionaries and repeating the words orally and written in learning both academic and general words. Nagy and Townsend (2012) pointed out that words are tools in the learning process. Strategies for learning academic vocabulary must use words as means for communicating and thinking about disciplinary contents. Therefore, learners must be provided with opportunities to use the instructed words for these purposes as they are learning them. Another study was carried out by Tran Huynh Thu Huong (2012) who examined the current situation of using strategies to broaden academic vocabulary and develop language skills of college student. The study found that the learners had a tendency in using less thinking strategies in learning academic vocabulary, and they did not use the right strategies on the process of learning academic vocabulary.

Given the fact that academic vocabulary is important in academic settings for university students and that few studies have been carried out to investigate the strategies for learning academic words, the current study was set out to fill this gap.

\section{RESEARCH METHODOLOGY}

The current study aimed at investigating strategies in learning academic English vocabulary by EFL university students. The research question is: What are EFL university students' strategies for learning academic vocabulary?

Survey research was used in the current study. It is a method to gather information about population groups to "learn about their characteristics, opinions, attitudes, or previous experiences" (Leedy \& Ormrod, 2005, p. 183). According to Brewer (2009), most survey research is conducted with a sample of respondents from the target population. Surveys are frequently used in education because they can provide constructive feedback and ideal for use in education (Brewer, 2009). Survey method is descriptive in nature; therefore, the researcher does not manipulate variables (Burns \& Grove, 2005). Besides these reasons, survey study was chosen for the current study because it can provide standardized measurement (Fowler, 2013) across all the responses, which ensures comparable information. Fowler (2013) also pointed out that a special purpose survey can provide information that is needed for research aims. In this study, the purpose is to collect responses to the specific topic of academic vocabulary learning strategies; thus, a survey study deems appropriate. As for psychological matters, paper surveys tend to be more private and less intimidating than face- 
to-face survey interviews because respondents do not have to talk directly to the interviewers. Besides, when completing the survey, respondents can take time to think about the questions in the survey. Moreover, a survey can contain several clusters which allows comparison of the responses.

Survey method has been popularly used in studies focusing vocabulary learning strategies. For example, Gu and Johnson (1996) investigated vocabulary learning strategies used by Chinese university learners of English and the relationship between their strategies and outcomes in learning English. In another study, Gu (2002) used survey to conduct a study on the relationship among gender, academic major, learning strategies and learning outcomes. Sex differences in L2 vocabulary learning strategies was investigated by Catalan (2003). More specifically, this study tried to find the differences in the number and the range of vocabulary strategies by male and female students. The survey study by Çelik and Toptaş (2010) aimed to examine vocabulary-learning strategies adopted by Turkish EFL students. It dwelled into the frequencies and helpfulness ratings of strategy use, strategy patterns, as well as their change for students across different language levels.

As mentioned earlier, this survey study adapted the taxonomy by Schmitt (2000) and Bramki and Williams (1984) and Chung and Nation (2003). The strategies included 6 clusters: Determination, social, memory, cognitive, metacognitive, and device-assisted strategies. The questionnaire contains 35 items for all the strategy groups. The items for the cluster of determination focuses on learning vocabulary by guessing context, from cognates, using reference materials, and analyzing affixes and roots. Social strategy cluster elicits responses on students' learning vocabulary by asking teachers or friends and studying word meanings with friends. Memory strategy emphasizes such techniques as grouping words into topics, forming imaginary, and using physical actions. Cognitive cluster targets at respondents' ways of learning vocabulary verbally and written, and making word lists or semantic maps, etc. Another cluster is meta-cognitive strategy which includes items on learning academic words by doing word tests and games, or using lexical familiarization devices. The last category for the strategy taxonomy used in the current study is device-assisted learning method asking whether learners use online-dictionaries and applications in vocabulary learning.

The participants were 132 EFL university students majoring in English interpretation and pedagogy. They are in their final year at university and voluntarily participated in the study. Their English proficiency level is from B2 to C1 level in the European Common Framework. They voluntarily participated in the current study.

\section{RESUlTS AND ANALYSIS}

First, Cronbach's Apha was run for the reliability statistics. It achieved .842 indicating high reliability of the questionnaire. Mean scores of the six clusters were also processed for comparison as shown in the following table:

TABLE 1.

MEAN SCORES OF SIX CLUSTERS

\begin{tabular}{|l|l|l|l|l|}
\hline Number $=\mathbf{1 3 2}$ & Min & Max & Mean & SD \\
\hline Cluster 1 & 2.50 & 5.00 & 3.89 & .453 \\
\hline Cluster 2 & 2.00 & 5.00 & 3.70 & .722 \\
\hline Cluster 3 & 2.20 & 5.00 & 3.68 & .564 \\
\hline Cluster 4 & 2.17 & 4.83 & 3.73 & .524 \\
\hline Cluster 5 & 2.67 & 5.00 & 3.75 & .480 \\
\hline Cluster 6 & 2.50 & 5.00 & 4.16 & .591 \\
\hline
\end{tabular}

As can be seen from the table, the mean scores of all clusters are rather high, above 3.68. Cluster 6 with using devices assisting learning vocabulary achieved the highest value of 4.16. Standard deviation for all clusters was at good value, except cluster 2 with a rather spreading out of the responses $(\mathrm{SD}=.722)$. All these statistics indicate the reliability of the tool used in this survey study.

The survey was then processed to examine the statistics of each group of strategy. The following table presents the statistics for the cluster of determination strategy.

TABLE 2.

DETERMINATION STRATEGY

\begin{tabular}{|l|l|l|l|}
\hline Number = 132 & Min & Max & Mean \\
\hline I learn academic English vocabulary by guessing context. & 2 & 5 & 3.81 \\
\hline I learn academic English vocabulary by guessing from cognates. & 2 & 5 & .711 \\
\hline I learn academic English vocabulary by using reference materials. & 2 & 5 & 3.85 \\
\hline I learn academic English vocabulary by analyzing affixes and roots. & 1 & 5 & .726 \\
\hline
\end{tabular}

Among the five items for determination strategy, learning academic English vocabulary by using reference materials, for example, using dictionaries achieves the highest mean score of 4.32 whereas the lowest value for learning academic English vocabulary by analyzing affixes and roots stands at 3.58. Other items have quite similar mean scores. However, the last item has the highest standard deviation implying that the response rate was rather spreading out. In contrast, the statement on learning academic English vocabulary by using reference materials obtains the lowest SD, at .669, indicating the response rate to be closer to the mean value. 
The following table displays the data regarding the social strategy group.

TABLE 3.

SOCIAL STRATEGY

\begin{tabular}{|l|l|l|l|}
\hline Number = 132 & Min & Max & Mean \\
\hline I learn academic English vocabulary by asking the teacher or classmates. & 2 & 5 & 3.67 \\
\hline $\begin{array}{l}\text { I learn academic English vocabulary by studying word meanings with } \\
\text { friends. }\end{array}$ & 2 & 5 & .852 \\
\hline
\end{tabular}

The finding for this cluster was rather similar for the two items referring to learning academic vocabulary by asking teachers or friends and by studying word meanings with friends. They achieve the mean scores of 3.67 and 3.73 respectively. Standard deviation for both items was rather similar. These statistics indicate consistence in responses given by the participants for the social strategy.

Another cluster was included in the survey to explore the memory strategy by the respondents. Table 4 below shows the result.

TABLE 4.

MEMORY STRATEGY

\begin{tabular}{|l|l|l|l|}
\hline Number = 132 & Min & Max & Mean \\
\hline $\begin{array}{l}\text { I learn academic English vocabulary by grouping the words according to } \\
\text { forms or topics. }\end{array}$ & 2 & 5 & 3.85 \\
\hline I learn academic English vocabulary by forming imaginary. & 1 & 5 & .824 \\
\hline I learn academic English vocabulary by using physical actions. & 2 & 5 & 3.55 \\
\hline $\begin{array}{l}\text { I learn academic English vocabulary by connecting new words to past } \\
\text { experience. }\end{array}$ & 2 & 5 & 3.29 \\
\hline $\begin{array}{l}\text { I learn academic English vocabulary by studying the spelling of the words } \\
\text { and speaking out loud the words while studying them. }\end{array}$ & 1 & 5 & 3.85 \\
\hline
\end{tabular}

Table 4 above presents the finding regarding the use of memory strategy. The mean values for all the questions in this cluster range from 3.55 to 3.91, showing the high and consistent level of responses of the participants for the cognitive strategy. However, their responses dispersed considerably with SD from .824 to .953. Among the items asked, it can be seen that the highest mean score for this cluster belongs to the statement referring to learning academic English vocabulary by studying the spelling of the words and speaking out loud the words has the highest mean score (M=3.91) whereas the statement about learning academic English vocabulary by using physical actions achieves the lowest $(\mathrm{M}=3.29)$.

The following table displays the result of the survey on the cognitive strategy.

TABLE 5.

COGNITIVE STRATEGY

\begin{tabular}{|l|l|l|l|}
\hline Number = 132 & Min & Max & Mean \\
\hline I learn English academic vocabulary by repeating words verbally and written. & 1 & 5 & 3.95 \\
\hline I learn academic English vocabulary by making word lists. & 1 & 5 & .919 \\
\hline $\begin{array}{l}\text { I learn academic English vocabulary by labeling English words on physical } \\
\text { objects. }\end{array}$ & 1 & 5 & 3.94 \\
\hline $\begin{array}{l}\text { I learn academic English vocabulary by keeping a journal to write word pairs } \\
\text { and semantic maps to understand the relationship between words. }\end{array}$ & 1 & 5 & 3.45 \\
\hline $\begin{array}{l}\text { I learn academic English vocabulary by deciding which words to focus on } \\
\text { and learn deeper. }\end{array}$ & 1 & 5 & 3.42 \\
\hline $\begin{array}{l}\text { I learn academic English vocabulary by using them in oral presentations and } \\
\text { academic discussions. }\end{array}$ & 2 & 3.70 \\
\hline
\end{tabular}

As can be seen from the table, the mean scores range from 3.42 to 3.95 indicating a rather high agreement of the respondents of the cognitive strategy group. The data also show that the respondents most preferred to repeat words verbally and written for learning them. However, the strategies of learning English academic vocabulary by repeating words verbally and written, making word lists, keeping a journal to write word pairs and semantic maps have a rather high standard deviation ranging from .906 to .950 , indicating that the responses spread out from the mean scores considerably.

Meta-cognitive strategy was also surveyed. The finding is presented in Table 6. 
TABLE 6.

META-COGNITIVE STRATEGY

\begin{tabular}{|c|c|c|c|c|}
\hline Number $=132$ & Min & Max & Mean & SD \\
\hline I learn academic English vocabulary by doing word tests. & 1 & 5 & 3.77 & .898 \\
\hline I learn academic English vocabulary by continuing to study the words all over the time. & 1 & 5 & 3.84 & .863 \\
\hline I learn English academic vocabulary by testing myself by using word games. & 1 & 5 & 3.50 & .904 \\
\hline $\begin{array}{l}\text { I learn English academic vocabulary by finding out writer's lexical familiarization devices } \\
\text { (definition and illustration, synonym, contrast with a more common meaning, and } \\
\text { restatement in comprehensive terms). }\end{array}$ & 1 & 5 & 3.70 & .907 \\
\hline I learn academic English vocabulary by reading academic texts. & 2 & 5 & 3.99 & .824 \\
\hline I learn academic English vocabulary by engaging in academic study. & 1 & 5 & 3.76 & .811 \\
\hline
\end{tabular}

Similar to the group of cognitive strategy, this cluster of meta-cognitive strategy obtains rather high mean scores ranging from 3.50 to 3.99. Standard deviation of the two items of learning English academic vocabulary by using word games and of learning English academic vocabulary by finding out writer's lexical familiarization devices. Reading academic texts to learn academic words was most chosen by the participants. However, word games were least reported in this survey.

The last cluster of academic learning strategy is referred to as "device-assisted" strategy. The finding is presented in the following table.

TABLE 7.

DEVICE-ASSISTED STRATEGY

\begin{tabular}{|c|c|c|c|c|}
\hline Number $=132$ & Min & Max & Mean & SD \\
\hline $\begin{array}{l}\text { I learn academic English vocabulary by using online dictionaries (e.g., } \\
\text { Dictionary.com, Merriam-Webster Online, AskOxford.com, Alpha } \\
\text { Dictionary, etc.) to look up definitions, examples, pictures, synonyms and } \\
\text { antonyms, etc. }\end{array}$ & 2 & 5 & 4.49 & .726 \\
\hline $\begin{array}{l}\text { I learn academic English vocabulary by using some applications such as } \\
\text { Memrise, Words with Friends, PowerVocab, Vocab Builder, and } \\
\text { Dictionary.com Flashcards, etc. to have fun quizzes and games to learn new } \\
\text { words. }\end{array}$ & 2 & 5 & 3.84 & .846 \\
\hline
\end{tabular}

Data from Table 7 shows that using online dictionaries was a popular choice among the respondents, with the mean score of 4.49 and using applications obtained a lower value at 3.84. However, both strategies were preferred by the respondents in the current study.

\section{DiSCUSSION AND CONCLUSION}

The findings of the current study indicate a high level of using all strategies in the taxonomy by Schmitt (2000). In addition, the statistics for the strategies adopted from and Bramki and Williams (1984) and Chung and Nation (2003) indicate the significantly high agreement of using devices assisting with learning and remembering vocabulary. This goes in line with the development of technology and creation of educational devices as well as their applications nowadays. It is interesting to see that the mean value for the cluster of device-assisted strategy obtains the highest statistics of 4.16 whereas the cluster of meta-cognitive group only reaches 3.75 , the lowest mean score among all the six groups of surveyed strategies. This finding illustrates that the respondents depended more on external factors in learning academic words than internal factors related to cognitive processes. This finding is in accordance with the study result by Tran Huynh Thu Huong (2012) who found that the learners had a tendency in using less thinking strategies in learning academic vocabulary.

Besides, in the current study, determination strategy overall has the second highest mean score among all the clusters. This finding indicates the preference of guessing meaning of academic words from contexts, cognates or word roots. Among all the items of the determination strategy, respondents' choice to learn academic English vocabulary by using reference materials achieved a very high mean value, at 4.32 .

The social strategy was overall at a rather significant value for mean score. However, it seems that students prefer to learn academic English vocabulary by studying word meanings with friends more than by asking for help from teachers (M=3.73 and 3.67 respectively). According to Schmitt (2000), teachers are the most popular reference for the social strategy in a variety of ways. However, in the current study, students tended to prefer to ask friends to teachers when encountering new words.

None of the previous studies reported the high level of learning the spelling of the academic words and speaking out loud the words. In this study, the finding for this strategy was at 3.91 for mean value which is the highest number in the memory group. It can be explained that the spelling of academic words is rather challenging for the respondents and they tended to learn how to spell the words to remember them.

As for other strategy categories, it is noticeable that the respondents reported a remarkable choice of learning academic vocabulary by repeating them verbally and written $(M=3.95)$. It can also be seen from the statistics that the respondents most preferred to use online dictionaries, for examples, Dictionary.com, Merriam-Webster Online, AskOxford.com, Alpha Dictionary, etc. to look up definitions, examples, pictures, synonyms and antonyms $(\mathrm{M}=4.49)$ 
whereas learning academic English vocabulary by using physical actions achieved the lowest mean score of 3.29. This finding could be explained that the respondents were university students so they had low preference to physical actions which might be more suitable for learning vocabulary with young learners. The high level of agreement of using dictionary of the current study reiterates previous findings pointed out by Akbari and Tahririan (2009) and LessardClouston (2008) who found that the participants mostly used consolidating, dictionaries and repeating the words orally and written in learning both academic and general words.

It can be concluded from the findings of the current study that in general, all the strategies in the taxonomy by Schmitt (2000), Bramki and Williams (1984) and Chung and Nation (2003) were reported to be used by the surveyed respondents. Besides, the learning strategies applied for academic vocabulary go in trend with technology development as learners have more devices to employ in the process of learning academic words. This also, to some extent, diminishes learners' use of cognitive strategy by linking new information with existing knowledge.

With the creation of more academic word lists for specific fields of studies nowadays (for some examples, see Hyland \& Tse, 2007; Lui \& Han, 2015; Martínez, Beck, \& Panza, 2009 and Yang, 2015), the adoption of a taxonomy for academic vocabulary strategies tends to be of practical values. When teachers or textbook writers introduce academic word lists, they should also provide learners with information how to learn these words, more specifically, the strategies to learn and remember the words.

It is even more practical if more tools are designed to assist learners to independently learn academic words. Such programs as on-line dictionaries, softwares to consolidate words, interactive programs that link learners on the globe in learning academic words would be beneficial to learners. Applications for guessing word meanings, retrieving words, remembering them as well as how to spell them correctly would be helpful to university students as the study findings show that they valued how to spell words correctly.

The list of learning strategies for academic words when compiled and given to learners can serve as a frame of reference that provides guidelines for teaching and independent study by students. Besides, the list of strategies can serve to inform course designers in designing materials, including academic vocabulary and developing learning activities in academic settings. When knowing the strategies for learning academic words, students will be more aware of what to do if they come across them in class reading, course readings, or reference materials. This will benefit the receptive vocabulary learning process of students. It is apparent that a systematized list of academic vocabulary learning strategies would make it practical for learners to refer to for both in class and independent learning.

In short, survey method was employed in the current study, allowing comparison responses across the clusters of academic vocabulary learning strategies. It enabled the collection of students' opinions on their preferred choice of the strategies in an unbiased way. Due to the scope of the paper, interview as well as diary data on academic vocabulary learning strategies was not reported. Future studies collecting responses on academic vocabulary learning strategies by EFL students from different countries would yield higher generalization in the findings.

\section{REFERENCES}

[1] Baumann, J. F., \& Graves, M. F. (2010). What is academic vocabulary? Journal of Adolescent \& Adult Literacy, 54(1), 4-12.

[2] Bramki, D., \& Williams, R. (1984). Lexical familiarization in economics text, and its pedagogic implications in reading comprehension. Reading in a foreign language, 2(1), 169-181.

[3] Brewer, E. W. (2009). Conducting survey research in education. In Handbook of research on e-learning applications for career and technical education: Technologies for vocational training (pp. 519-533). IGI Global.

[4] Burns, N., \& Grove, S. K. (2005). Study guide for the practice of nursing research: conduct, critique, and utilization. Philadelphia: Saunders.

[5] Catalan, R. M. J. (2003). Sex differences in L2 vocabulary learning strategies. International Journal of Applied Linguistics, 13(1), 54-77.

[6] Çelik, S., \& Toptaş, V. (2010). Vocabulary learning strategy use of Turkish EFL learners. Procedia-Social and Behavioral Sciences, 3, 62-71.

[7] Chung, T. M., \& Nation, P. (2004). Identifying technical vocabulary. System, 32(2), 251-263.

[8] Coxhead, A. (2000). A new academic word list. TESOL quarterly, 34(2), 213-238.

[9] Corson, D. (1997). The learning and use of academic English words. Language learning, 47(4), 671-718.

[10] Fowler Jr, F. J. (2013). Survey research methods. Los Angeles: Sage publications.

[11] Gu, Y., \& Johnson, R. K. (1996). Vocabulary learning strategies and language learning outcomes. Language learning, 46(4), 643-679.

[12] Gu, Y. (2002). Gender, academic major, and vocabulary learning strategies of Chinese EFL learners. RELC journal, 33(1), 3554.

[13] Gu, P. Y. (2003). Vocabulary learning in a second language: Person, task, context and strategies. TESL-EJ, 7(2), 1-25.

[14] Hyland, K., \& Tse, P. (2007). Is there an " academic vocabulary"? TESOL Quarterly, 41(2), 235-254.

[15] Konecni, E. (1978). Scientific and technical rhetoric. In L. Trimble and M. Todd Trimble (Eds.). English for specific purposes: Science and technology. Oregon: Oregon University Press.

[16] Kramsch, C. J. (1979). Word watching: Learning vocabulary becomes a hobby. Foreign Language Annals, 12(2), 153-158.

[17] Lawson, M. J., \& Hogben, D. (1996). The vocabulary-learning strategies of foreign-language students. Language learning, 46(1), 101-135.

[18] Leedy, P. D., \& Ormrod, J. E. (2005). Practical research. New York: Pearson Custom. 
[19] Lessard-Clouston, M. (2008). Strategies and success in technical vocabulary learning: Students' approaches in one academic context. Indian Journal of Applied Linguistics, 34(2), 31-63.

[20] Liu, J., \& Han, L. (2015). A corpus-based environmental academic word list building and its validity test. English for Specific Purposes, 39, 1-11.

[21] Martínez, I. A., Beck, S. C., \& Panza, C. B. (2009). Academic vocabulary in agriculture research articles: A corpus-based study. English for Specific Purposes, 28, 183-198.

[22] Marzano, R. J., \& Pickering, D. J. (2005). Building academic vocabulary: Teacher's manual. Association for Supervision and Curriculum Development. 1703 North Beauregard Street, Alexandria, VA 22311-1714.

[23] Mukoroli, J. (2011). Effective vocabulary teaching strategies for the English for academic purposes ESL classroom. MA thesis at the SIT Graduate Institute, Brattleboro, Vermont.

[24] Nagy, W., \& Townsend, D. (2012). Words as tools: Learning academic vocabulary as language acquisition. Reading Research Quarterly, 47(1), 91-108.

[25] Nation, I. S. P. (2001). Learning vocabulary in another language. New York: Cambridge University Press.

[26] Nushi, M., \& Jenabzadeh, H. (2016). Teaching and Learning Academic Vocabulary. California Linguistic Notes, 40 (2), $51-70$.

[27] Oxford, R.L. (1990). Language learning strategies and beyond: A look at strategies in the context of styles. In S.S. Magnan (Ed.), Shifting the instructional focus to the learner (pp. 35-55). Middlebury, VT: Northeast Conference on the Teaching of Foreign Languages.

[28] Schmitt, N., \& McCarthy, M. (1997). Vocabulary: Description, acquisition and pedagogy. Cambridge: Cambridge University Press.

[29] Schmitt, N. (2000). Vocabulary in language teaching. NY: Ernst Klett Sprachen.

[30] Townsend, D. (2009). Building academic vocabulary in afterschool settings: Games for growth with middle school English language learners. Journal of Adolescent \& Adult Literacy, 53(3), 242-251. doi:10.1598/JAAL.53.3.5.

[31] Thurston, J., \& Candlin, C. N. (1998). Concordancing and the teaching of the vocabulary of academic English. English for specific purposes, $17(3), 267-280$.

[32] Trần Huỳnh Thu Hương. (2012). An investigation into the vocabulary learning strategy of ESP students in College of Foreign Language - The University of Danang. Tuyển tập Báo cáo Hội nghị Sinh viên Nghiên cứu Khoa học lần thứ 8 Đại học Đà Nẵng (Reports of Research by Students at the University of Da Nang).

[33] William, R. C. (1980). Lexical Familiarization in content area textbooks. In. L.J. Chapman (Ed). The Reader and the Text. London. Heinemann.

[34] Yang, M. N. (2015). A nursing academic word list. English for Specific Purposes, 37, 27-38.

Lê Phạm Hoài Hương is an associate professor in the English Faculty of Hue University of Foreign Languages, Hue University in Vietnam. Her research interests include teaching and learning vocabulary, sociocultural theory and classroom interactions. 